\title{
Synthesis and some properties of alkenyl carbanions stabilised by an $\alpha$-boron atom
}

\author{
Andrew Pelter , Keith Smith ${ }^{*}$ and Kevin Jones \\ Department of Chemistry, University College of Swansea, Singleton Park, Swansea SA2 8PP, UK.
}

Abstract. Methods for making boron-stabilised alkenyl carbanions and some of their reactions are presented. The calculated geometry and stabilisation energy of $\mathrm{H}_{2} \mathrm{BC}=\mathrm{CH}_{2}$ are given.

We have previously investigated the production and properties of carbanions, $R_{2}^{1} B C \mathrm{H}^{2}$, derived from hindered organoboranes. Such carbanions were predicted to have a considerable stabilisation energy, ${ }^{2}, 3$ a prediction which has been verified. ${ }^{1}$ We wondered whether carbanions, $\mathrm{R}_{2}{ }_{\mathrm{BC}} \overline{\mathrm{C}}=\mathrm{CHR}{ }^{2}$ would also be stabilised by an overlap that would lead to an allene like species (Fig. 1), in contrast with $R_{2} B C_{4}{ }^{2}$ which has a planar alkene like structure.'

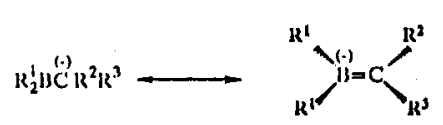

ALKLNE TYPE STRUCTURE

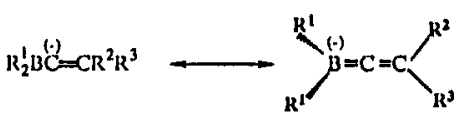

ALLENE TYIE STRUCTURE

Figure 2 .
Preliminary HF/4-31+G Calculations (Dr D. Parry)

$\mathrm{It}_{2} \mathrm{H} \cdot \mathrm{CH}=\mathrm{CH}_{2}$

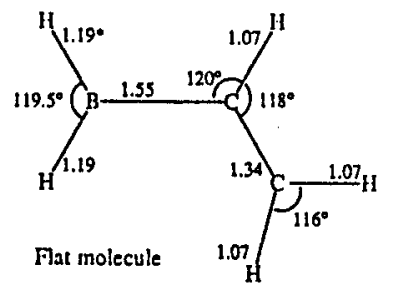

$\mathrm{H}_{2} \mathrm{BC}=\mathrm{CH}_{2}$

Dihedral angle between terminal hydrogens on boron and carbon is almost exactiy $90^{\circ}$.

*All bond lengths in $\AA \quad$ Figure 2 .

Figure 2 shows the most favoured conformations of $\mathrm{H}_{2} \mathrm{BC}=\mathrm{CH}_{2}$ and its parent compound $\mathrm{H}_{2} \mathrm{BC}=\mathrm{CH}_{2}$. The carbanion does indeed have an allene like structure, with a B-C bond length of $1.42 \mathrm{~A}$. This is in line with a C-B bond length of $1.44 \AA$ for $\mathrm{Mes}_{2} \mathrm{~B}-\mathrm{CH}_{2}$, said to show complete $\mathrm{C}=\mathrm{B}$ character.

Figure 3 presents the stabilisation energies of $\mathrm{X}-\overline{\mathrm{C}}=\mathrm{CH}_{2}\left(\mathrm{X}=\mathrm{BH}_{2}, \mathrm{CH}_{3}\right)$ relative to $\mathrm{H}-\overline{\mathrm{C}}=\mathrm{CH}_{2}$. It can be seen that boron has a significant stabilising effect, whilst $\mathrm{CH}_{3}$ is very slightly destabilising. These results are in line with those for $\mathrm{CH}_{2}-\mathrm{X}\left(\mathrm{X}=\mathrm{BH}_{2}, \mathrm{CH}_{3}\right)^{2}$ as shown in Figure 3.

\section{HF/4.31 + G CALCULATIONS ON ALKENYL ANIONS (D. Parry)}

Proton Affinities

\begin{tabular}{lccc} 
Anion & PA/a.u. & PA/Kcal mol & SE/Kcal mol $^{-1}$ \\
$\mathrm{CH}_{2}=\overline{\mathrm{C}}-\mathrm{H}$ & -0.6788 & -427 & 0 \\
$\mathrm{CH}_{2}=\overline{\mathrm{C}}-\mathrm{BH}_{2}$ & -0.6121 & -385 & -42 \\
$\mathrm{CH}_{2}=\mathrm{C}-\mathrm{CH}_{3}$ & -0.6808 & -428 & +1 \\
\hline Compare $^{2}$ with stabilisation energies for $\mathrm{CH}_{2}-\mathrm{BH}_{2}$ and $\mathrm{CH}_{2}-\mathrm{CH}_{3}$ of -54.7 and $+5.7 \mathrm{Kcal} \mathrm{mol}^{-1}$ respectively
\end{tabular}


We decided to see whether we could produce such anions and characterise them physically and chemically. For their generation we used a displacement approach, either of tin or of silicon. The first approach is illustrated in Figure 4 in which tin is displaced to give a lithio-species (the required "anion"), in which the lithium, if bonded, might retain some of the stereochemistry of the original geminal dimetallo-species. Attack by an electrophile followed by oxidation would yield a ketone, with no stereochemical ambiguities, and we decided to use this to monitor the sequence. At a later stage, hydrolysis of the trapped intermediate would give insight into its stereochemistry.

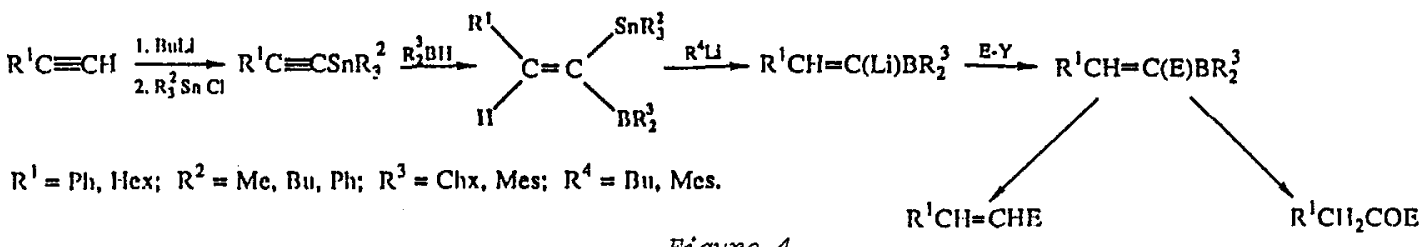

Figure 4.

A similar sequence involves the displacement of silicon, using $F$ (Fig. 5). The difference lies in that in this case the anion is created as a 'free' anion, with a Bu ${ }_{4}^{+}$counter ion. We felt it worthwhile to examine both possibilities.

$\mathrm{R}^{\prime}=\mathrm{PH}_{1}, \mathrm{Hex} ; \mathrm{R}^{2}=\mathrm{Cl}$, Mcsi $\mathrm{Ex} \mathrm{H}_{2} \mathrm{O}, \mathrm{Mel}$

We used phenylethyne and oct-1-yne as prototypes of aromatic and aliphatic substituted ethynes. Figure 6 illustrates some results starting with phenylethyne. Both dicyclohexylborane and dimesitylborane were used and the substituents on tin were varied from $\mathrm{Me}$ to $\mathrm{Bu}$ to $\mathrm{Ph}$. With the trimethyltin substituent, the use of mesityllithium as hindered base was clearly superior to the use of butyllithium, presumably due to inhibition of ate complex formation on boron. This reached its climax when dimesitylborane was the hydroborating agent and mesityllithium was used as base. Excellent yields of ketone were produced on methylation and oxidation, this presumably paralleling the production of the desired carbanion. When triphenyltin derivatives were used, very little carbanion was produced (Fig. 7).

PliC $\equiv$ CSnMle, ; Mel as trapping agent

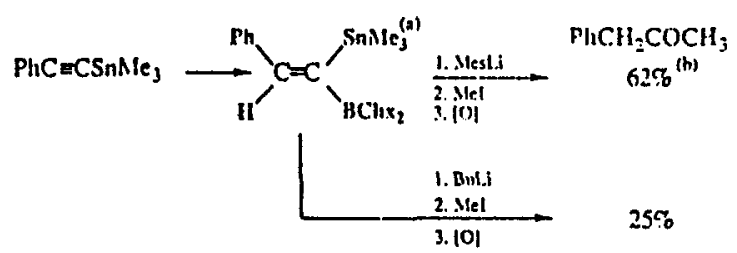

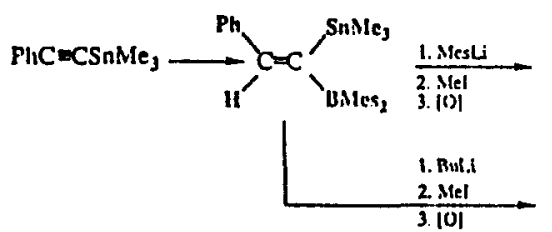

$\mathrm{PhC} \equiv \mathrm{CSnlBu}_{3}$; Mcl as trapping agent

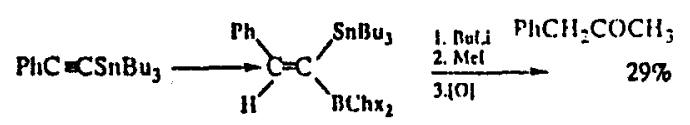


PhC $=\mathrm{CSuI}^{\prime} \mathrm{H}_{3} ; \mathrm{Mel}$ as trappling agent

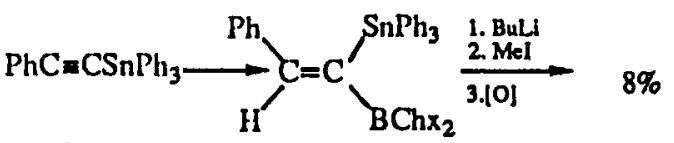

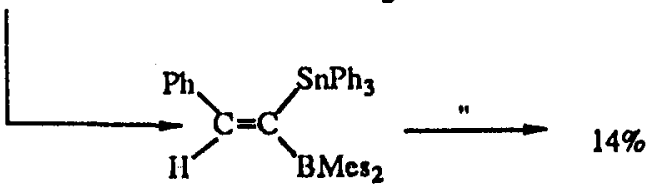

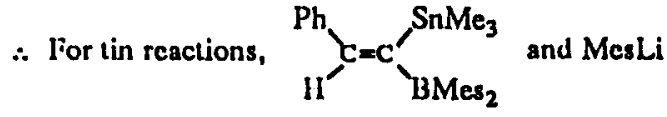

best combination by far.

Figure 7.
$\mathrm{PhC}_{\mathrm{C}} \equiv \mathrm{CSiMc}_{3} ; \mathrm{Mel}$ as trapping agent

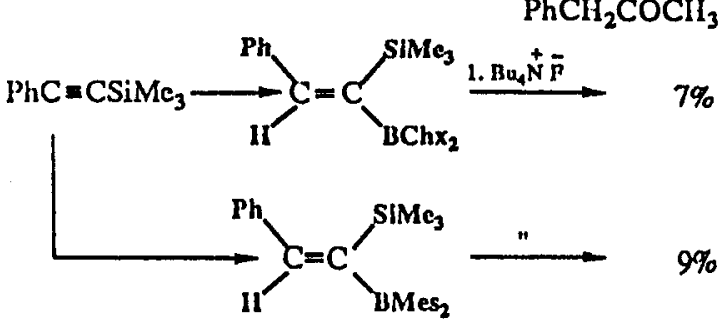

In this casc attack on boron rather than silicon, to give silicon stabilised carbanion.

\section{Figure 8.}

The silicon species were of great interest as the fluoride efficiently attacked at boron rather than silicon (Fig, 8), to give an important route to silicon-stabilised carbanions! Thus for the aromatic species only one combination of organometallics and base efficiently yields the required carbanion. This involves hydroboration of the trimethyltin alkyne with $\mathrm{Mes}_{2}{ }^{\mathrm{BH}}$ followed by reaction with MesLi..

Starting with oct-1-yne, either trimethyltin or trimethylsilicon were effective adjuncts, and either BuLi or $\mathrm{Bu}_{4} \mathrm{NF}$ could be used to produce the carbanion (Fig. 9). The simple and readily available combination of trimethylsilicon and dicyclohexylboron is standardly used.

Other alkylating agents such as benzyl bromide, allyl bromide and even $n$-heptyl iodide (slow reaction) can be used to trap the carbanions, the overall synthetic process being an effective conversion of alkynes to a variety of ketones.

Protonation as a trap for the 'carbanions' produced from the tin reactions could be deceptive.

Aldehydes were produced, presumably by hydrolysis (which might or might not involve a carbanion) followed by oxidation. The contrast with methylation is shown in Figure 10.

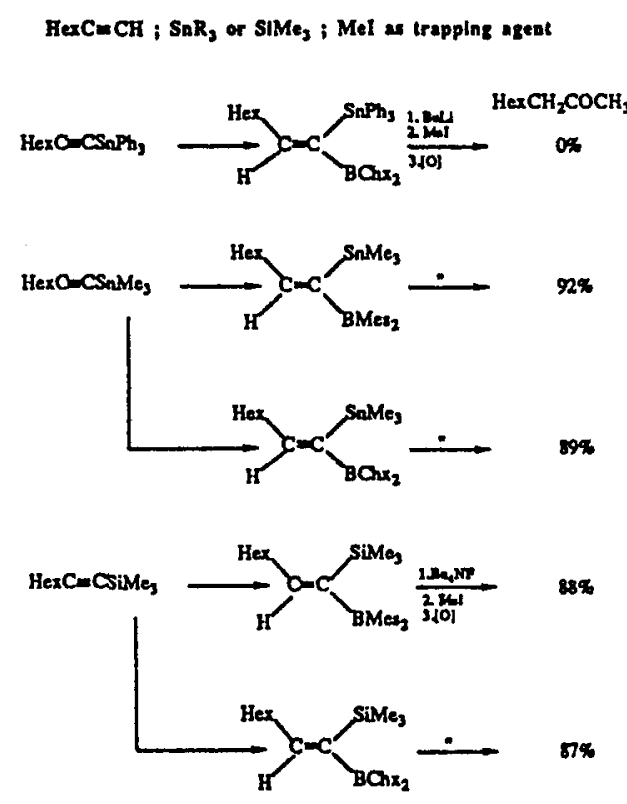

Figure 9.

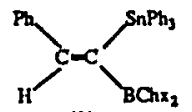

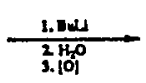

$\mathrm{PhCH}_{2} \mathrm{CHO}$

$70 \%$.

(1)

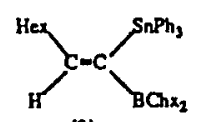

(2)

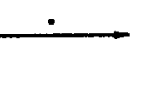

$\mathrm{Hex} \mathrm{CH}_{2} \mathrm{ClYO}_{6}$

Compare (1)

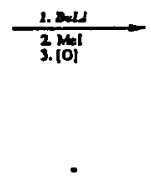

$\mathrm{PhCH}_{3} \mathrm{COCH}_{6}$

(2)

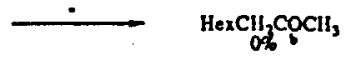

These compounds do nol form enions with BuLi, and therefore the aldehydes arise from hydrolysis / oxidacion.

W bolend w DNP b) Oe yiald

Figure 20. 
The silicon species does not suffer from this defect (Fig. 11) but the nature of the displacing agent is important. In addition to $\mathrm{Bu}_{4} \mathrm{NF}$, we used a combination of $\mathrm{BF}_{3} \cdot \mathrm{OEt}_{2}$ and water $(1: 1)$ to generate anhydrous HF and other uncharacterised species.

This reagent gives reasonable yields of aldehydes, probably not via the alkenyl anions.

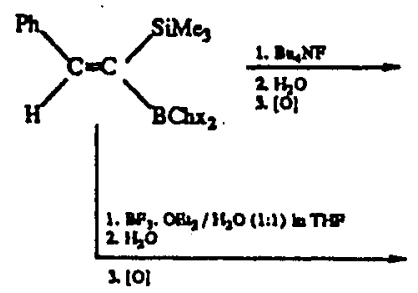

$\mathrm{PhCH}_{2} \mathrm{CHO}$

$7 x^{*}$<smiles>CCCC(C)C</smiles>

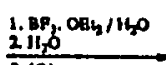

$70 x^{*}$

Compare

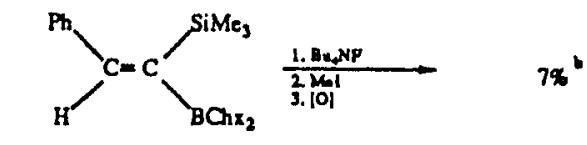

Wholend $u$ DNP b) 0 e

Figure 27.

We now have defined conditions for producing a variety of alkenyl anions stabilised by an $\alpha$-boron atom. Their further characterisation and reactions with other electrophiles, particularly carbonyl compounds will be reported later. The stereochemistry of the carbanions is not known, but protonation of $\mathrm{PhCH}=\mathrm{CBMes}$, yields the $E$-alkene only.

\section{REFERENCES}

1. A. Pelter, B. Singaram, L. Williams and J. W. Wilson, Tetrahedron Lett., 24, 623 (1983).

2. G. W. Spitznagel, T. Clark, J. Chandrasekhar and P. von Rague-Schleyer, L. Comput. Chem., 3, 363 (1982).

3. A. Pross, D. J. DeFrees, B. A. Levi, S. K. Pollack, L. Radom and W. J. Hehre, L. Org. Chem., 46, 1693 (1981).

4. M. M. Olstead, P. P. Power, K. J. Weese and R. J. Doedens, L.Am. Chem. Soc., 109, 2541 (1987). 